\title{
Effects of Deliberate Ingestion of Organophosphate or Paraquat on Brain Stem Auditory-Evoked Potentials
}

\author{
Sudheera Sammanthi Jayasinghe • \\ Kithsiri Dedduwa Pathirana
}

Published online: 11 August 2011

(C) The Author(s) 2011. This article is published with open access at Springerlink.com

\begin{abstract}
Organophosphate (OP) and paraquat (PQ) ingestion is a serious health problem. A common pathology behind $\mathrm{OP}$ or PQ poisoning is the generation of reactive oxygen species (ROS) which is known to cause ototoxicity. The aim of the study was to identify the effects of deliberate ingestion of OP or PQ on brain stem auditory-evoked potentials (BAEPs). Consecutive patients with deliberate self-poisoning with OP or PQ who were admitted to a secondary and a tertiary care hospital in the Southern province of Sri Lanka and matched controls were recruited. BAEPs were performed at 1 week (first assessment) and 6 weeks (second assessment) after the exposure. Interpeak latencies of I-III, III-V, and I-V were measured. There were 70 and 28 patients in the OP and PQ arms with the mean age of $32 \pm 12$ and $29 \pm 12$ years, respectively. There were 70 controls and their mean age was $33 \pm 12$ years. In OP and PQ poisoning, 53/70 and 18/28 came for the second assessment, respectively. The interpeak latency was not statistically different in the controls vs the first assessment, controls vs the second assessment, and the first vs the second assessment. There were no significant lesions in the auditory pathway in OP or PQ poisoned
\end{abstract}

\author{
S. S. Jayasinghe $(\varangle)$ \\ Department of Pharmacology, Faculty of Medicine, \\ University of Ruhuna, \\ Matara, Sri Lanka \\ e-mail: sudheerasj@yahoo.com

\section{S. S. Jayasinghe} \\ South Asian Clinical Toxicology Research Collaboration, \\ Department of Medicine, Faculty of Medicine, \\ University of Peradeniya, \\ Peradeniya, Sri Lanka \\ S. S. Jayasinghe $\cdot$ K. D. Pathirana \\ Clinical Neuroscience Center, Department of Medicine, \\ Faculty of Medicine, University of Ruhuna, \\ Matara, Sri Lanka
}

patients. The generation of ROS within the perilymphatic space following the ingestion of OP or PQ may not be sufficient to cause lesions in the auditory pathway. Further studies with the assessment of auditory threshold are needed.

Keywords Evoked potentials · Organophosphorus compounds $\cdot$ Paraquat $\cdot$ Suicide

\section{Introduction}

Organophosphate (OP) and paraquat (PQ) pesticide ingestion is a serious health problem especially in developing countries, since OP compounds were involved in $76 \%$ of pesticide poisoning $[1,2]$ and $\mathrm{PQ}$ self-poisoning has the highest case fatality $(65 \%)$ for any poisoning in Sri Lanka [3]. The two important pathologies behind PQ toxicity are the generation of reactive oxygen species (ROS; superoxide anion, hydrogen peroxide, hydroxyl radical) and the depletion of NADPH which is necessary for normal function [4]. Dandapani et al. reported oxidative damage following OP poisoning [5]. Widespread and robust effects of chlorpyrifos on the genes involved in antioxidant activity have been shown by Slotkin et al. [6]. ROS are associated with drugs (cisplatin, aminoglycosides) $[7,8]$ and noise-induced $[9,10]$ cochlear pathology. Animal studies showed that PQ treatment leads to change in hearing threshold, outer and inner hair cell loss [11]. Progressively increasing delay in auditory event-related potential has been reported in vegetable farmers with longterm exposure to OP [12]. In contrast, Kimura et al. reported that there was no statistically significant difference in auditory-evoked responses in farmers who were exposed to various pesticides compared to the controls [13]. The aim of the study was to identify the effects of deliberate ingestion of OP or PQ on brain stem auditory-evoked potentials (BAEPs). 
Fig. 1 Electrode placement in BAEP

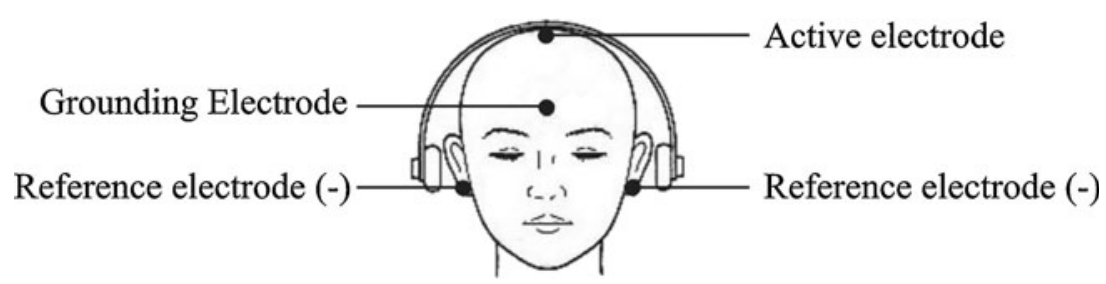

\section{Materials and Methods}

A cohort study was conducted with matched controls. Consecutive patients with deliberate self-poisoning with $\mathrm{OP}$ or PQ who were admitted to a secondary and a tertiary care hospital in the Southern province of Sri Lanka were recruited. The study was approved by the ethical review committee, Faculty of Medicine, University of Ruhuna, Sri Lanka. An informed consent was obtained from the patients. BAEPs were performed at 1 week (the first assessment) and 6 weeks (the second assessment) after the exposure.

Ingestion of OP was confirmed with cholinergic features or patients who were treated at peripheral hospitals with atropine. PQ ingestion was confirmed with positive urine to sodium dithionate test $[14,15]$.

The control group was recruited from persons accompanying the patients to the tertiary care hospital. Age, gender and occupation-matched healthy volunteers who did not have a history of acute pesticide exposure were recruited. The controls were matched to \pm 3 years of the age of test individuals. BAEP was performed only once for the controls. Participants with history of diabetes, neuropathies head injury, and ear infections were excluded from the study.

BAEP is an electrophysiological method that can be used for neurotoxicity testing of auditory function [16]. A computer-based Neuropack $\mathrm{S}_{1}$ electromyography (EMG)/EP measuring system MEB-9400 (Nihon Kohden) was used for the BAEP. A piece of cotton moistened with alcohol was used to clean the patient's skin where the electrodes were attached and the skin rubbed with dry gauze to remove any moisture and gel from the skin. Recording electrodes (active and reference) and grounding electrodes were attached on the patient's head with Elefix paste (Fig. 1). The patient was kept on a chair relaxed with eyes closed. To avoid EMG of the neck, patients were asked not to move their head. To avoid EMG of the chin, patient was
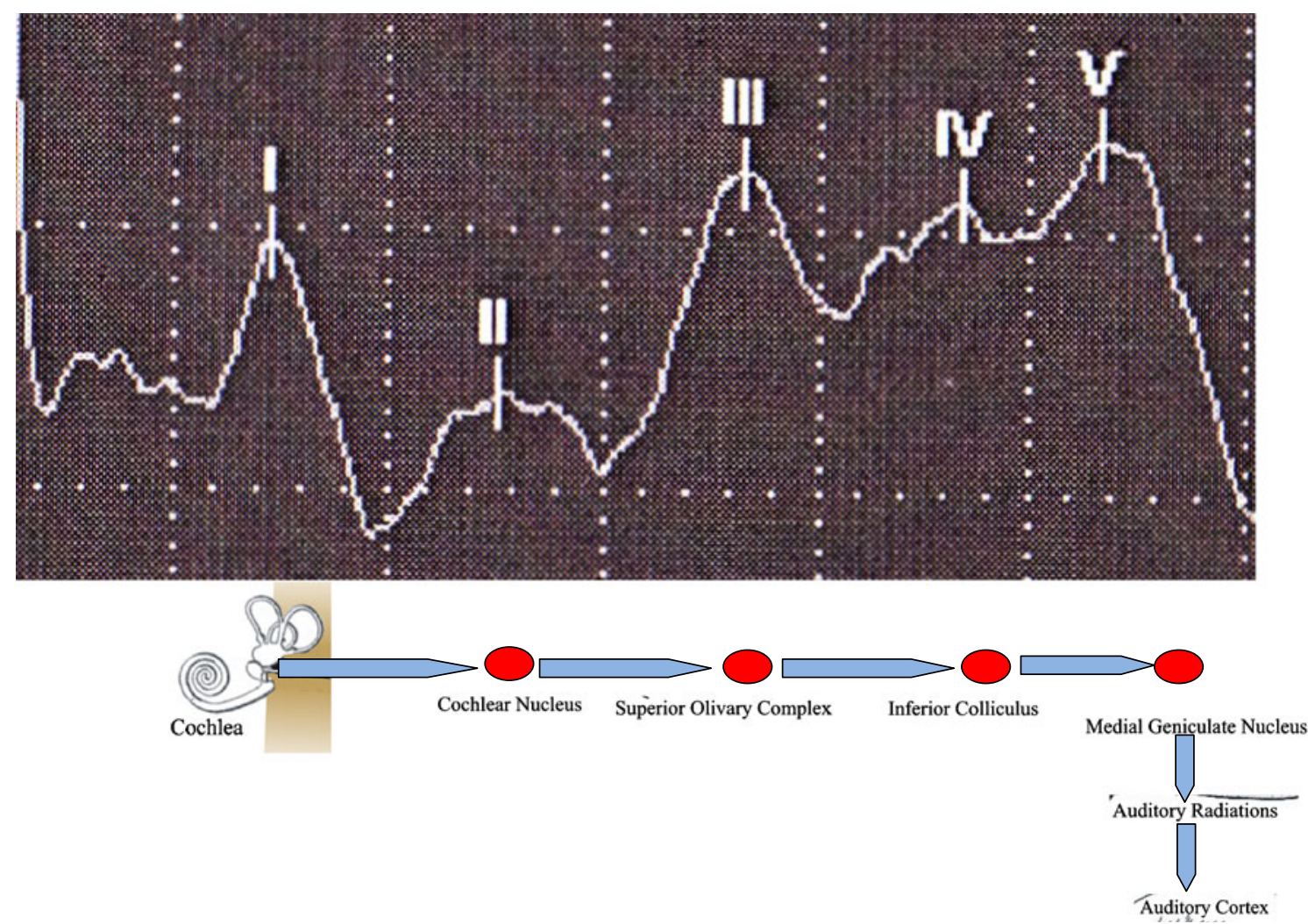

Fig. 2 Probable sites of generation of the human BAEP [16] 
Table 1 The mean latency difference of BAEP in the test and the control groups in OP poisoning

\begin{tabular}{|c|c|c|c|c|c|c|c|c|c|}
\hline & \multirow{2}{*}{$\begin{array}{l}\text { Control } \\
\text { group, } \\
N=70\end{array}$} & \multicolumn{2}{|l|}{ Test group } & \multicolumn{3}{|c|}{ Mean differences } & \multicolumn{3}{|l|}{$95 \% \mathrm{CI}$} \\
\hline & & $\begin{array}{l}1 \mathrm{st} \\
\text { assessment, } \\
N=70\end{array}$ & $\begin{array}{l}\text { 2nd } \\
\text { assessment, } \\
N=53\end{array}$ & $\begin{array}{l}\text { Controls } \\
\text { vs } 1 \text { st } \\
\text { assessment }\end{array}$ & $\begin{array}{l}\text { Controls } \\
\text { vs } 2 \text { nd } \\
\text { assessment }\end{array}$ & $\begin{array}{l}1 \text { st assessment } \\
\text { vs } 2 \text { nd } \\
\text { assessment }\end{array}$ & $\begin{array}{l}\text { Controls } \\
\text { vs } 1 \text { st } \\
\text { assessment }\end{array}$ & $\begin{array}{l}\text { Controls } \\
\text { vs } 2 \text { nd } \\
\text { assessment }\end{array}$ & $\begin{array}{l}\text { 1st assessment } \\
\text { vs } 2 \text { nd } \\
\text { assessment }\end{array}$ \\
\hline \multicolumn{10}{|c|}{ Right side } \\
\hline I-III & $2.2 \pm 0.6$ & $2.1 \pm 0.2$ & $2.1 \pm 0.2$ & 0.07 & 0.11 & 0.04 & -0.04 to 0.1 & -0.1 to 0.05 & -0.08 to 0.07 \\
\hline III-V & $1.8 \pm 0.2$ & $1.9 \pm 0.2$ & $1.8 \pm 0.5$ & 0.02 & 0.08 & 0.05 & -0.04 to 0.09 & -0.08 to 0.06 & -0.09 to 0.05 \\
\hline $\mathrm{I}-\mathrm{V}$ & $4.0 \pm 0.3$ & $4.0 \pm 0.2$ & $3.9 \pm 0.2$ & 0.01 & 0.03 & 0.04 & -0.03 to 0.1 & -0.1 to 0.06 & -0.1 to 0.07 \\
\hline \multicolumn{10}{|c|}{ Left side } \\
\hline I-III & $2.1 \pm 0.2$ & $2.1 \pm 0.2$ & $2.1 \pm 0.2$ & 0.03 & 0.03 & 0.005 & -0.2 to 0.07 & -0.05 to 0.2 & -0.2 to 0.1 \\
\hline III-V & $1.8 \pm 0.2$ & $1.9 \pm 0.2$ & $1.8 \pm 0.2$ & 0.03 & 0.007 & 0.02 & -0.09 to 0.1 & -0.2 to 0.05 & -0.07 to 0.1 \\
\hline $\mathrm{I}-\mathrm{V}$ & $3.9 \pm 0.2$ & $3.7 \pm 0.2$ & $3.9 \pm 0.2$ & 0.06 & 0.03 & 0.03 & -0.09 to 0.1 & -0.08 to 0.1 & -0.15 to 0.07 \\
\hline
\end{tabular}

asked to open his/her mouth slightly. The headphones were kept on the head. The hi-cut and the low-cut filters were set to $3 \mathrm{kHz}$ and $100 \mathrm{~Hz}$, respectively. The skinelectrode contact impedance was kept below $5 \mathrm{k} \Omega$. The stimulation intensity was $90 \mathrm{~dB}$ and 1,000 stimulations were averaged. Latency was measured in milliseconds. Interpeak latencies of $1-111,111-\mathrm{V}$, and $1-\mathrm{V}$ were measured (Fig. 2) [16, 17]. ANOVA and Post Hoc comparison were used for the analysis.

\section{Results}

There were 70 (50 males) patients recruited following OP ingestion and 28 (21 males) patients following PQ ingestion. The mean [standard deviation (SD)] age of the OP and PQ patients was 32 (12) and 29 (12) years, respectively. There were 70 controls and their mean (SD) age was 33 (12) years. In OP poisoning, 53/70 came for the second assessment, and in PQ poisoning, 18/28 came for the second assessment.

\section{BAEP in OP Poisoning}

The differences of the mean latency of I-III, III-V, and I-V were prolonged in the test group compared to the controls except in right side 1-111 difference in the first assessment of the test, right side $1-111$ and $1-\mathrm{V}$ difference in the first and the second assessment in the test group compared to the controls. None of the differences were statistically significant (Table 1).

\section{BAEP in PQ Poisoning}

Table 2 shows the difference of mean latency of I-III, III-V, and $\mathrm{I}-\mathrm{V}$. There was no significant difference detected in the test group compared to the controls.

\section{Discussion}

The current study did not show any significant difference in the interpeak latencies of BAEP in the patients compared to the controls. Very few human studies have examined

Table 2 The mean latency difference of BAEP in the test and the control groups in PQ poisoning

\begin{tabular}{|c|c|c|c|c|c|c|c|c|c|}
\hline & \multirow{2}{*}{$\begin{array}{l}\text { Control } \\
\text { group, } \\
N=70\end{array}$} & \multicolumn{2}{|l|}{ Test group } & \multicolumn{3}{|c|}{ Mean differences } & \multicolumn{3}{|l|}{$95 \% \mathrm{CI}$} \\
\hline & & $\begin{array}{l}1 \text { st } \\
\text { assessment, } \\
N=28\end{array}$ & $\begin{array}{l}\text { 2nd } \\
\text { assessment, } \\
N=18\end{array}$ & $\begin{array}{l}\text { Controls } \\
\text { vs } 1 \text { st } \\
\text { assessment }\end{array}$ & $\begin{array}{l}\text { Controls } \\
\text { vs } 2 \text { nd } \\
\text { assessment }\end{array}$ & $\begin{array}{l}\text { 1st assessment } \\
\text { vs } 2 \text { nd } \\
\text { assessment }\end{array}$ & $\begin{array}{l}\text { Controls } \\
\text { vs } 1 \mathrm{st} \\
\text { assessment }\end{array}$ & $\begin{array}{l}\text { Controls } \\
\text { vs } 2 \text { nd } \\
\text { assessment }\end{array}$ & $\begin{array}{l}1 \text { st assessment } \\
\text { vs } 2 \text { nd } \\
\text { assessment }\end{array}$ \\
\hline \multicolumn{10}{|c|}{ Right side } \\
\hline I-III & $2.2 \pm 0.6$ & $2.1 \pm 0.3$ & $2.1 \pm 0.3$ & 0.09 & 0.09 & 0.01 & -0.4 to 0.2 & -0.4 to 0.4 & -0.4 to 0.4 \\
\hline III-V & $1.8 \pm 0.2$ & $1.9 \pm 0.2$ & $1.8 \pm 0.2$ & 0.02 & 0.01 & 0.01 & -0.1 to 0.1 & -0.1 to 0.1 & -0.1 to 0.1 \\
\hline $\mathrm{I}-\mathrm{V}$ & $4.0 \pm 0.3$ & $3.9 \pm 0.3$ & $3.9 \pm 0.3$ & 0.01 & 0.03 & 0.01 & -0.2 to 0.2 & -0.2 to 0.2 & -0.2 to 0.2 \\
\hline \multicolumn{10}{|c|}{ Left side } \\
\hline I-III & $2.1 \pm 0.2$ & $2.1 \pm 0.2$ & $2.3 \pm 1.3$ & 0.03 & 0.3 & 0.3 & -0.3 to 0.3 & -0.6 to 0.03 & -0.6 to 0.1 \\
\hline III-V & $1.8 \pm 0.2$ & $1.8 \pm 0.2$ & $1.8 \pm 0.1$ & 0.05 & 0.01 & 0.05 & -0.1 to 0.06 & -0.1 to 0.1 & -0.9 to 0.1 \\
\hline $\mathrm{I}-\mathrm{V}$ & $3.9 \pm 0.2$ & $3.9 \pm 0.3$ & $3.9 \pm 0.2$ & 0.01 & 0.002 & 0.01 & -0.1 to 0.2 & -0.2 to 0.1 & -0.1 to 0.2 \\
\hline
\end{tabular}


ototoxic effects with pesticide exposure. No studies have assessed the ototoxic effects following acute exposure to OP. The number of the participants in the PQ arm was small and this may not be adequate to come to firm conclusions. The number of participants in the OP arm may have not provided adequate power to detect statistical differences.

BAEP is a sensory-evoked potential used to assess the integrity of the auditory pathway from the eighth nerve to the auditory cortex [16]. The interpeak latencies (I-III, III-V, and $\mathrm{I}-\mathrm{V}$ ) of BAEP provide a straightforward method to roughly localize lesions in the auditory pathway [16].

Animal studies by Bielefeld et al. and Harris et al. showed shifting of evoked potential threshold and loss of inner and outer hair cells following the application of 10,5 , and $3 \mathrm{mM}$ of PQ to cochlea through a surgical incision $[9,11]$. The current study did not look into the auditory threshold level.

Clerici and Yang demonstrated the disruption of generation and transmission of afferent cochlear signals by generation of reactive oxygen species within the perilymphatic space with artificial perilymph and hydrogen peroxide [7]. Even though both OP and PQ produce reactive oxygen species after ingestion, the concentration of substances reaching the perilymphatic space may not be sufficient to damage the cochlea.

Kimura et al. studied the effects of the event-related evoked potentials in tobacco farmers who were exposed to different pesticides including OP. They did not see any significant effects on the event-related evoked potentials [13].

\section{Conclusion}

There were no significant lesions in the auditory pathway in $\mathrm{OP}$ or PQ poisoned patients compared to the matched controls. The generation of reactive oxygen species within the perilymphatic space following the ingestion of $\mathrm{OP}$ or PQ may not be sufficient to cause lesions in the auditory pathway. However, damage to the inner and outer hair cells cannot be excluded. Further studies with the assessment of auditory threshold in acute OP or PQ poisoning are needed.

\begin{abstract}
Acknowledgments This study was supported by Wellcome Trust and NHMRC International Collaborative Research Grant (GR071669MA). We would like to acknowledge the participants, the consultants who encouraged their patients for the study, administrative staff and health care professionals at the Karapitiya Teaching Hospital and the Matara General Hospital, heads and the staff members of the Department of Pharmacology and the Department of Medicine, Faculty of Medicine, University of Ruhuna, Sri Lanka, the members and the Clinical Research Assistances of the South Asian Clinical Toxicology Research Collaboration. A special word of thank is extended to Professors NA Buckley, AH Dawson, Anoja Fernando, PL Ariyananda, and Dr. Bilesha Perera.
\end{abstract}

Conflicts of interest The authors declare that there are no conflicts of interest.
Open Access This article is distributed under the terms of the Creative Commons Attribution Noncommercial License which permits any noncommercial use, distribution, and reproduction in any medium, provided the original author(s) and source are credited.

\section{References}

1. Jayarathnam J, Senevirathna RSDA, Copplestone JF (1982) Survey of pesticide poisoning in Sri Lanka. Bull World Health Organ 60:615-619

2. Jayarathnam J (1990) Acute pesticide poisoning: a major global health problem. World Health Stat Q 43:139-144

3. Gawarammana IB, Dawson AH (2010) Peripheral burning sensation: a novel clinical marker of poor prognosis and higher plasma-paraquat concentrations in paraquat poisoning. Clin Toxicol (Phila) 48:347-349

4. Bus JS, Gibson JE (1984) Paraquat: model for oxidant-initiated toxicity. Environ Health Perspect 55:37-46

5. Dandapani M, Zachariah A, Kavitha MR, Jeyaseelan L, Oommen A (2003) Oxidative damage in intermediate syndrome of acute organophosphorous poisoning. Indian J Med Res 117:253-259

6. Slotkin TFS, Frederic J, Seidler FJ (2009) Oxidative and excitatory mechanisms of developmental neurotoxicity: transcriptional profiles for chlorpyrifos, diazinon, dieldrin, and divalent nickel in PC12 cells. Environ Health Perspect 117:587-596

7. Clerici WJ, Yang L (1996) Direct effects of intraperilymphatic reactive oxygen species generation on cochlear function. Hear Res 101:14-22

8. Priuska EM, Schacht J (1995) Formation of free radicals by gentamicin and iron and evidence for an iron/gentamicin complex. Biochem Pharmacol 50:1749-1752

9. Harris KC, Bielefeld E, Hu BH, Henderson D (2006) Increased resistance to free radical damage induced by low-level sound conditioning. Hear Res 213:118-129

10. Ohlemiller KK, Wright JS, Dugan LL (1999) Early elevation of cochlear reactive oxygen species following noise exposure. Audiol Neurootol 4:229-236

11. Bielefeld EC, Hu BH, Harris KC, Henderson D (2005) Damage and threshold shift resulting from cochlear exposure to paraquatgenerated superoxide. Hear Res 207:35-42

12. Dassanayake T, Gawarammana IB, Weerasinghe V, Dissanayake PS, Pragaash S, Dawson A, Senanayake N (2009) Auditory eventrelated potential changes in chronic occupational exposure to organophosphate pesticides. Clin Neurophysiol 120:1693-1698

13. Kimura K, Yokoyama K, Sato H, Nordin RB, Naing L, Kimura S, Okabe S, Maeno T, Kobayashi Y, Kitamura F, Araki S (2005) Effects of pesticides on the peripheral and central nervous system in tobacco farmers in Malaysia: studies on peripheral nerve conduction, brainevoked potentials and computerized posturography. Ind Health 43:285-294

14. Chen GH, Lin JL, Huang YK (2002) Combined methylprednisolone and dexamethasone therapy for paraquat poisoning. Crit Care Med 30:2584-2587

15. Lin JL, Leu ML, Liu YC, Chen GH (1999) A prospective clinical trial of pulse therapy with glucocorticoid and cyclophosphamide in moderate to severe paraquat-poisoned patients. Am J Respir Crit Care Med 159:357-360

16. Otto D, Hudnell K, Boyes W, Janssen R, Dyer R (1988) Electrophysiological measures of visual and auditory function as indices of neurotoxicity. Toxicology 49:205-218

17. Legatt AD, Arezzo JC, Vaughan HG (1988) The anatomic and physiologic bases of brain stem auditory evoked potentials. Neurol Clin 6:681-704 